\title{
Spinal and corticospinal excitability in response to reductions in skin and core temperatures via whole-body cooling
}

\author{
Daryl M.G. Hurrie, Morteza Talebian nia, Kevin Power, Katinka Stecina, Phillip Gardiner, Evan Lockyer, \\ and Gordon G. Giesbrecht
}

\begin{abstract}
Cold stress impairs fine and gross motor movements. Although peripheral effects of muscle cooling on performance are well understood, less is known about central mechanisms. This study characterized corticospinal and spinal excitability during surface cooling, reducing skin $\left(T_{\text {sk }}\right)$ and esophageal $\left(T_{e s}\right)$ temperatures. Ten subjects ( 3 females) wore a liquid-perfused suit and were cooled $\left(9^{\circ} \mathrm{C}\right.$ perfusate, $\left.90 \mathrm{~min}\right)$ and rewarmed $\left(41^{\circ} \mathrm{C}\right.$ perfusate, $\left.30 \mathrm{~min}\right)$. Transcranial magnetic stimulation (eliciting motor evoked potentials [MEPs]), as well as transmastoid (eliciting cervicomedullary evoked potentials [CMEPs]) and brachial plexus (eliciting maximal compound motor action potentials $\left[\mathrm{M}_{\text {max }}\right]$ ) electrical stimulation, were applied at baseline, every 20 min during cooling, and following rewarming. Sixty minutes of cooling reduced $T_{\text {sk }}$ by $9.6^{\circ} \mathrm{C}(P<0.001)$, but $T_{\text {es }}$ remained unchanged $(P=0.92)$. $T_{\text {es }}$ then decreased by $\sim 0.6^{\circ} \mathrm{C}$ in the next $30 \mathrm{~min}$ of cooling $(P<0.001)$. Eight subjects shivered. During rewarming, shivering was abolished, and $T_{\text {sk }}$ returned to baseline, while $T_{\text {es }}$ did not increase. During cooling and rewarming, $\mathrm{M}_{\max }, \mathrm{MEP}$, and $\mathrm{MEP} / \mathrm{M}_{\max }$ remained unchanged from baseline. However, $\mathrm{CMEP}$ and $\mathrm{CMEP} / \mathrm{M}_{\max }$ increased during cooling by $\sim 85 \%$ and $79 \%(P<0.001)$, respectively, and remained elevated post-rewarming. The results suggest that spinal excitability is facilitated by reduced $T_{\text {sk }}$ during cooling and reduced $T_{\text {es }}$ during warming, while corticospinal excitability remains unchanged. ClinicalTrials.gov ID: NCT04253730.
\end{abstract}

Novelty:

- This is the first study to characterize corticospinal and spinal excitability during whole-body cooling and rewarming in humans.

- Whole body cooling did not affect corticospinal excitability.

- Spinal excitability was facilitated during reductions in both skin and core temperatures.

Key words: transcranial magnetic stimulation, cold performance, thermoregulation.

Résumé : Le stress dû au froid altère la motricité fine et globale. Bien que les effets périphériques du refroidissement musculaire sur la performance soient bien établis, on en sait moins sur les mécanismes centraux. Cette étude présente l'excitabilité corticospinale et spinale pendant le refroidissement de la peau, la diminution de la température cutanée (" $T_{\text {sk }}$ ) et œsophage ( $\mathrm{T}_{\text {es }}$ ). Dix sujets ( 3 femmes) portant une combinaison perfusée de liquide sont refroidis (perfusat $9{ }^{\circ} \mathrm{C}, 90 \mathrm{~min}$ ) et réchauffés (perfusat $41{ }^{\circ} \mathrm{C}, 30 \mathrm{~min}$ ). Une stimulation magnétique transcrânienne (déclenchant des potentiels évoqués moteurs ["MEP »]) ainsi qu'une stimulation électrique transmastoïdienne (déclenchant des potentiels évoqués cervicomédullaires ["CMEP »]) et du plexus brachial (déclenchant des potentiels d'action motrice composés maximaux [" $\mathbf{M}_{\max }$ ") sont appliquées au début, toutes les $20 \mathrm{~min}$ pendant le refroidissement et après le réchauffement. Soixante minutes de refroidissement réduisent la $T_{\text {sk }}$ de $9,6{ }^{\circ} \mathrm{C}(P<0,001)$ mais la $T_{\text {es }}$ reste inchangée $(P=0,92)$. La $T_{\text {es }}$ diminue ensuite d'environ $0,6{ }^{\circ} \mathrm{C}$ au cours des 30 minutes suivantes de refroidissement $(P<0,001)$. On note un frissonnement chez huit sujets. Pendant le réchauffement, les frissons sont abolis et la $T_{\mathrm{sk}}$ revient à la ligne de base tandis que la $T_{\text {es }} n$ 'augmente pas. Pendant le refroidissement et le réchauffement, $\mathrm{M}_{\max }$, MEP et MEP/ $\mathrm{M}_{\max }$ restent inchangés par rapport à la ligne de base. Cependant, CMEP et $\mathrm{CMEP} / \mathrm{M}_{\max }$ augmentent pendant le refroidissement d'environ $85 \%$ et $79 \%(P<0,001)$ respectivement et restent élevés après le réchauffement. Les résultats suggèrent que l'excitabilité spinale est facilitée par la diminution de la $T_{\text {sk }}$ pendant le refroidissement et de la $T_{\text {es }}$ pendant le réchauffement, tandis que l'excitabilité corticospinale reste inchangée. ClinicalTrials.gov ID : NCT04253730. [Traduit par la Rédaction]

Received 13 May 2021. Accepted 22 September 2021.

D.M.G. Hurrie and M. Talebian nia. Faculty of Kinesiology and Recreation Management, University of Manitoba, Winnipeg, MB R3T 2N2, Canada. K. Power and E. Lockyer. School of Human Kinetics and Recreation, Memorial University of Newfoundland, St. John's, NL A1C 5S7, Canada.

K. Stecina. Department of Physiology \& Pathophysiology, University of Manitoba, Winnipeg, MB R3E 0J9, Canada.

P. Gardiner. Faculty of Kinesiology and Recreation Management, University of Manitoba, Winnipeg, MB R3T 2N2, Canada; Department of Physiology \& Pathophysiology, University of Manitoba, Winnipeg, MB R3E 0J9, Canada.

G.G. Giesbrecht. Faculty of Kinesiology and Recreation Management, University of Manitoba, Winnipeg, MB R3T 2N2, Canada; Department of Emergency Medicine, University of Manitoba, Winnipeg, MB R3E 0W2, Canada.

Corresponding author: Gordon G. Giesbrecht (email: gordon.giesbrecht@umanitoba.ca).

() 2021 The Author(s). This work is licensed under a Creative Commons Attribution 4.0 International License (CC BY 4.0), which permits unrestricted use, distribution, and reproduction in any medium, provided the original author(s) and source are credited. 
Les nouveautés :

- Il s'agit de la première étude à décrire l'excitabilité corticospinale et spinale pendant le refroidissement et le réchauffement du corps entier chez l'homme.

- Le refroidissement du corps entier n'affecte pas l'excitabilité corticospinale.

- L'excitabilité de la colonne vertébrale est facilitée lors des réductions de la température cutanée et centrale.

Mots-clés : stimulation magnétique transcrânienne, performance au froid, thermorégulation.

\section{Introduction}

Significant cold stress can negatively impact sport training (Hurrie and Giesbrecht 2018) and performance (Castellani and Tipton 2015), workplace health and safety (Anttonen et al. 2009), and survival (Lloyd and Havenith 2016). Cold performance, safety, and survival depend on the ability to control and sustain muscular activity (Castellani and Tipton 2015). Whole body cooling can reduce skin $\left(T_{\text {sk }}\right)$, muscle $\left(T_{\text {mus }}\right)$ and core $\left(T_{\text {co }}\right)$ temperatures impairing both fine and gross motor performance, which is relevant in all of these situations (Giesbrecht and Bristow 1992; Giesbrecht et al.1995; Cheung 2003).

Local mechanisms for cold-induced performance decrements include decreases in excitation contraction coupling (Faulkner et al. 1990), nerve conduction velocity (de Jong et al. 1966), and muscle contraction velocity (Oksa et al. 1996). However, little is known about the changes in spinal (SE) and corticospinal (CSE) excitability that accompany cold stress.

Evidence regarding spinal excitability is sparse and limited to local cooling. Ankle joint cooling (20-30 min ice application) increases the maximal Hoffman-reflex $\left(\mathrm{H}_{\max }\right)$ normalized to the maximal compound motor action potential $\left(\mathrm{M}_{\max }\right)$ in the soleus; this effect persisted for 90 min following ice removal (Palmieri-Smith et al. 2007), thus indicating increased spinal excitability (Pierrot-Deseilligny and Mazevet 2000; Palmieri-Smith et al. 2007; McNeil et al. 2013); this also stimulated increased serum norepinephrine. Similar responses have been observed with leg cooling (Oksa et al. 2000; Hopkins and Stencil 2002; Dewhurst et al. 2005; Palmieri-Smith et al. 2007) and ankle cooling in young women (Oksa et al. 2000; Hopkins and Stencil 2002; Dewhurst et al. 2005; Palmieri-Smith et al. 2007).

The effects of cooling on corticospinal excitation (indicated by changes in motor evoked potential [MEP] amplitude, which is elicited by transcranial magnetic stimulation [TMS]) are mixed. Localized hemi-scalp cooling (reducing $T_{\text {sk }}$ to $\sim 19{ }^{\circ} \mathrm{C}$ for $10 \mathrm{~min}$ ) reduced MEP amplitudes of the first dorsal interosseous muscle by $\sim 8 \%-12 \%$ for $20 \mathrm{~min}$ following wrap removal (Tremblay et al. 2015). Finger cooling $\left(10^{\circ} \mathrm{C}\right.$ gel pack for $5 \mathrm{~min}$ ) had no effect on group mean responses, but analyses of individual responses revealed that about one-half of the subjects experienced decreased MEP amplitude (indicating corticospinal inhibition), while about one-third of subjects experienced increased MEP amplitude (indicating excitation) (Ansari et al. 2018b). These effects were not persistent after cooling only 1 finger, but persisted for up to $10 \mathrm{~min}$ after cooling 4 fingers (Ansari et al. 2018a). A greater cooling stimulus (full immersion in $8^{\circ} \mathrm{C}$ water for $60 \mathrm{~min}$ ) reduced both $T_{\text {sk }}$ and $\mathrm{T}_{\text {co }}$ (to $34.8{ }^{\circ} \mathrm{C}$ ) but did not change the mean $\mathrm{MEP} / \mathrm{M}_{\max }$ of the biceps brachii (Cahill et al. 2011); individual responses were not reported, so the variability of responses is not known.

The contrasting results of these latter studies may be due to several differences in protocol, including the magnitude of both $T_{\text {sk }}$ and $T_{\text {co }}$ reductions, and the amount of surface area, duration, and location of cooling. For example, it is not known if cooling the scalp, which is close to the area of magnetic stimulation, contributed to the decrease in MEP amplitude. Furthermore, none of these studies utilized an independent measure of spinal excitability to determine if changes in corticospinal transmission were due to cortical/supraspinal and/or spinal changes (Taylor and Gandevia 2004).

These results are not necessarily representative of the wholebody cooling experienced during typical cold exposure, or do not include measures of both spinal and corticospinal excitability. To our knowledge, no study has simultaneously characterized corticospinal and spinal excitability during sustained whole-body cooling. The purpose of this study was to test the hypothesis that whole-body cooling will not affect corticospinal excitability, but will increase spinal excitability.

\section{Materials and methods}

\section{Ethical approval and participants}

The experimental protocol was approved by the University of Manitoba Education/Nursing Research Ethics Board (Protocol \#E2018:047 [HS21827]). The study was registered with ClinicalTrials.gov (ID\# NCT04253730). Prior to participation, signed informed consent forms were obtained.

All subjects were free of neurological disorders and any diseases where cold exposure was contraindicated. All were right hand dominant, as determined by responses to the Edinburgh Handedness Inventory (Oldfield 1971), as this is the side available for measurement with our equipment. All subjects were moderately physically active and trained 3-5 times/week.

In order to avoid ceiling effects and to detect both facilitation and inhibition at an equal chance, the MEP/Mmax or CMEP/Mmax ratios were adjusted at the beginning of each experiment to be $30 \% \pm 20 \%$ (Crone et al. 1990). To achieve a $90 \%$ power when using a t-test to detect a statistically significant difference at a minimum of $10 \%$ change between 2 groups of data $(\mathrm{a}=0.05$, 1-tailed, expected standard deviation $=0.05$ ); the sample size was calculated to be 8 (using SigmaStat4.0). Twelve subjects ( 8 males and 4 females) were recruited to allow for potential dropouts. They were $26 \pm 6$ y old; $172.3 \pm 8.6 \mathrm{~cm}$ tall; weighed $72.4 \pm 10.5 \mathrm{~kg}$; and had $15.9 \% \pm 7.9 \%$ body fat $(n=12)$.

\section{Study overview}

This study included familiarization and intervention trials and used a 2-piece liquid-perfused suit (LPS) to determine the effects of whole-body surface cooling on spinal and corticospinal excitability.

\section{Thermal manipulations}

Cooling and rewarming were accomplished with an LPS (AllenVanguard, ON, Canada) worn directly on the skin. The suit was perfused either from a closed loop recirculating chiller (VWR 6200M Series, VWR North America, ON, Canada) circulating $9{ }^{\circ} \mathrm{C}$ coolant (Polycool EG-25, Polyscience, IL, USA), or during rewarming, from a $\sim 530 \mathrm{~L}$ water reservoir with a pump circulating $41^{\circ} \mathrm{C}$ water. The transition between the 2 sources took $\sim 2-3 \mathrm{~min}$. The suit was donned after heat flux discs, and electromyography (EMG) electrodes were affixed to the skin surface prior to any other assessments. Three 6-inch wide, elastic tensor bandages (Elastowrap) were wrapped over the LPS on the torso to ensure that consistent close contact with the skin was maintained; this suit fit tightly enough to ensure close contact with the arms and legs. 


\section{Measurement of thermophysiological outcomes}

For each trial, males wore tight-fitting shorts, while females wore a sports bra in addition to tight-fitting shorts. This clothing ensured that the maximal skin contact was made with the LPS. The subjects were instrumented in ambient laboratory temperature $\left(\sim 22^{\circ} \mathrm{C}\right)$.

The following thermophysiological variables were measured in the intervention trial. $T_{\text {sk }}\left({ }^{\circ} \mathrm{C}\right)$ was measured using heat flux disks (Concept Engineering, Old Saybrook, CT) at 7 sites on the left side of the body. Weighted mean $T_{\mathrm{sk}}$ was calculated using the following sites (which represented areas with the following regional percentages): forehead (head, 7\%), abdomen (torso, 35\%), lower arm (arm, 14\%), dorsal hand (5\%), anterior thigh (upper leg, 19\%), anterior calf (lower leg, 13\%), and foot (7\%), according to previous work in our lab and Layton et al. (Layton et al. 1983). Esophageal temperature $\left(\mathrm{T}_{\mathrm{es}} ;{ }^{\circ} \mathrm{C}\right)$ was monitored using an esophageal thermocouple (Mon-atherm, Mallinckrodt Medical Inc., St Louis, MO, USA) inserted at the level of the heart. This site provides the best non-invasive correlation with intracardiac temperature (Hayward et al.1984).

A subjective thermal sensation scale was used to rate thermal sensation on a 0 to 8 point scale in 0.5 point increments $(0$, very cold; to 8, very hot) (Gagge et al. 1967).

\section{Muscle electromyography (EMG)}

For both trials, muscle EMG was measured with disposable selfadhesive bipolar Ag/AgCl surface electrodes (Kendall Meditrace, Mansidel, MA, USA) affixed to the skin over the muscle belly $2 \mathrm{~cm}$ apart (centre to centre). Skin preparation for all electrodes followed accepted practices (Stefanelli et al. 2019). Briefly, hair was removed by shaving the skin, and the skin was abraded with fine grit sandpaper and further cleaned with a 70\% isopropyl alcohol wipe. EMG electrodes monitored the activity of the biceps brachii, triceps brachii, and rectus femoris. EMG data were used to detect shivering, as described in the Data Analysis.

EMG signals were sampled at $1 \mathrm{kHz}$ during the MVCs and 8-min EMG blocks were used to assess shivering activity (Haman 2004; Imbeault et al. 2013; Blondin et al. 2017). EMG signals were sampled at $5 \mathrm{kHz}$ during the stimulation blocks (Stefanelli et al. 2019). All EMG signals were amplified $(\times 300$; CED 1902, Cambridge Electronic Design Ltd., Cambridge, UK) and filtered using a 3-pole Butterworth filter with bandpass frequencies of $10-1000 \mathrm{~Hz}$ (Stefanelli et al. 2019). A $60 \mathrm{~Hz}$ notch filter was applied to remove the harmonic distortion. Signals were analog-to-digitally converted using a CED 1401 interface (Cambridge Electronic Design Ltd., Cambridge, UK) and analyzed using Signal software (Cambridge Electronic Design Ltd., Cambridge, UK).

\section{Measurement of force and muscular performance}

For both trials, the subjects were seated upright in a custombuilt rigid stimulation chair with hips and knees flexed to $90^{\circ}$. Feet rested shoulder width apart, flat on a platform placed in front of the chair. Two straps fastened the body to the chair; one was fastened across the upper torso at the level of the xiphoid process, while the second strap was fastened across the upper thigh. A third strap secured the head to the headrest.

For the right biceps brachii (elbow flexors) MVC, the shoulder was slightly abducted and placed at $0^{\circ}$ so that the forearm rested on a padded arm rest with the elbow flexed at $90^{\circ}$. The forearm was held midway between supination and neutral positions. The forearm was strapped at the wrist to a load cell (Model 60001, S-Beam Load Cell, Intertechnology Inc., ON, Canada) that was conditioned with an inline amplifier at $1000 \mathrm{~Hz}$ (SGCM-401, Intertechnology Inc., ON, Canada). The load cell was calibrated with known weights, and during trials, force was displayed on a monitor for subject feedback. Forces were analog-to-digitally converted (CED 1401 interface, Cambridge Electronic Design Ltd., Cambridge, UK) and analyzed using Signal software (Cambridge Electronic Design Ltd. Cambridge, UK).
Subjects performed two 5-s MVCs of the right elbow flexors with maximum force production, with contractions separated by 2 min of rest. If the difference between the 2 MVCs was more than $5 \%$, further contractions were performed until 2 of the highest MVC values were within this range (Aboodarda et al. 2015). Strong verbal encouragement and visual feedback of the force tracing were provided during the contractions. A 3-s submaximal contraction (5\% MVC) of the elbow flexors was performed during all stimulation blocks. This increased the probability of successfully obtaining MEPs and CMEPs (Taylor et al. 2002; Pearcey et al. 2014) and provided a consistent level of muscle activation, which may have otherwise been affected by the dynamic background EMG activity known to occur with cooling and shivering (Israel and Pozos 1989; Bell et al. 1992).

\section{Measurement of corticospinal excitability}

\section{Brachial plexus electrical stimulation and hot spotting}

Erb's point "hot spotting" was conducted to ensure optimal placement of the electrodes for brachial plexus stimulation. Electrical stimulations were delivered via a constant current electrical stimulator (Digitimer, DS7AH, Hertfordshire, UK). Hot spotting consisted of delivering a fixed electrical pulse (singlet pulse, $50 \mathrm{~mA}$, $200 \mu$ s duration) using a cathode (Motor Point Pen, Compex Canada, Mississauga, ON, Canada) with an anode electrode (self-adhesive $\mathrm{Ag} / \mathrm{AgCl}$ surface electrode, Meditrace, Kendall, Mansidel, MA, USA) fixed to the acromion process. After each stimulation, the pen was moved to a new location within the supraclavicular fossa. The site that resulted in the greatest compound muscle action potential $\left(\mathrm{M}_{\text {wave }}\right)$ amplitude measured from the biceps muscle EMG was used for cathode placement for brachial plexus stimulation.

Brachial plexus stimulation was then delivered via 2 surface electrodes to evoke a maximal compound muscle action potential $\left(\mathrm{M}_{\max }\right)$ measured from the biceps brachii EMG. Current pulses were delivered as a singlet (square wave pulse, $200 \mu$ s duration). Stimulation intensity began at $50 \mathrm{~mA}$ and gradually increased until $M_{\max }$ was elicited. Supramaximal stimulation intensity (20\% greater than that required to elicit $\mathrm{M}_{\max }$ ) (Aboodarda et al. 2015; Stefanelli et al. 2019) was used throughout the remainder of the trial.

\section{Transcranial magnetic stimulation (TMS)}

Transcranial magnetic stimulation was delivered using a circular coil (15 cm outside diameter) powered by a Magstim 200 magnetic stimulator (Magstim Company Ltd., Dyfed, UK). Stimulation of the motor cortex with the magnetic coil applied at the vertex produces a motor-evoked potential (MEP) measured from the biceps brachii EMG. The vertex was identified as the intersection of the halfway distance between the nasion and inion and the tragus-totragus measurements. This point was marked with indelible ink or a drop of whiteout on dark skin. The coil was held atop the subject's head in a mechanical arm with current flow preferentially activating the left primary motor cortex so that measures could be obtained in the right biceps (dominant arm) of subjects. While subjects performed a $5 \%$ MVC, stimulation intensity began at $40 \%$ maximal stimulator output (MSO) and gradually increased until the MEP amplitude was between $10 \%$ and $20 \%$ of $\mathrm{M}_{\max }$ in at least 8 of 12 stimulations (Pearcey et al. 2014). The \%MSO used to elicit this amplitude was used for the remainder of the trial.

\section{Transmastoid electrical stimulation (TMES)}

TMES results in a cervicomedullary evoked potential (CMEP), which provides an index of spinal excitability and can be used in conjunction with motor cortex and peripheral nerve stimulation to better characterize the excitability of the entire corticospinal pathway (Taylor and Gandevia 2004).

Transmastoid electrical stimulation was delivered using an electrical stimulator (Digitimer, DS7R, Hertfordshire, UK) delivered through disposable self-adhesive bipolar $\mathrm{Ag} / \mathrm{AgCl}$ surface electrodes (Meditrace, Kendall, Mansidel, MA, USA). Stimulation 
Fig. 1. (Top) Protocol for the cooling trial. Time 0 is the start of cooling; maximum voluntary contractions (MVCs) are of both elbow and leg extensor muscle groups; maximum compound action potential $\left(\mathrm{M}_{\text {max }}\right)$; electromyography (EMG) (8-min recording of biceps, triceps, pectoralis major, and rectus femoris muscles); SB, stimulation block (transcranial magnetic stimulation, $n=10$; Transmastoid electrical stimulation, $n=8$; brachial plexus, $n=2$ ). (Bottom) Presence or absence of shivering (as indicated by increased EMG activity) for each subject throughout the cooling trial. Each EMG block was visually inspected for obvious increases in EMG activity (see Fig. 2). In the first rewarming block (88-96 $\mathrm{min}$ ) the 2 symbols indicate the presence or absence of shivering at the beginning, and end of, the EMG block. Note, subjects 2 and 7 were recruited but did not complete the experiment, therefore $n=10$. SE, spinal excitability.

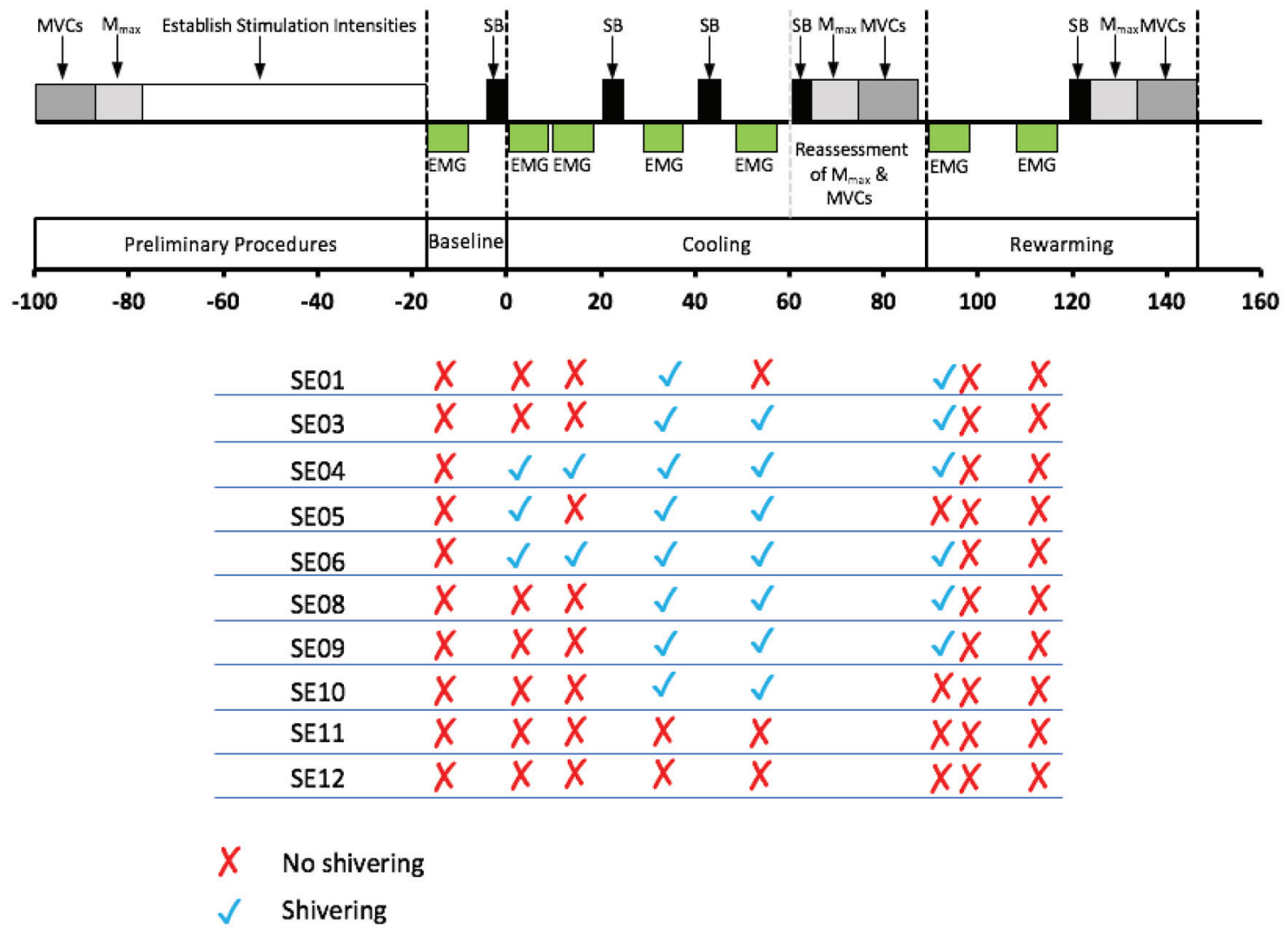

was delivered to 2 electrodes positioned on the left and right mastoid processes (back of the neck at the base of the skull), evokes a cervicomedullary evoked potential (CMEP) measured from the biceps brachii EMG. Current pulses were delivered as a singlet (square wave pulse, $200 \mu$ s duration) (Stefanelli et al. 2019). Intensity began at $50 \mathrm{~mA}$ and was gradually increased until CMEP amplitudes were matched to MEP amplitudes in at least 8 of the 12 stimulations. Care was taken to monitor the CMEP latency for signs of ventral root stimulation, which would be evidenced by a decreased latency $(\sim 2 \mathrm{~ms})$ when stimulation intensity is increased (Taylor and Gandevia 2004). Matching the CMEP to MEP amplitude ensures that similar portions of the motoneuron pool were activated by the respective stimuli (Taylor et al. 2002; Pearcey et al. 2014).

\section{Stimulation block}

Each stimulation block included 10 TMS stimuli, 8 TMES stimuli, and 2 brachial plexus stimuli delivered during a 5\% MVC contraction of the biceps brachii. The 20 stimuli occurred at 10-s intervals and were randomized (Stefanelli et al. 2019) with Signal 7.0 software (Cambridge Electronic Design Ltd. Cambridge, UK). Subjects were given visual feedback of the force output on a monitor and were instructed to contract and hold the 5\% MVC until they received the stimulation, which occurred after $3 \mathrm{~s}$ of contraction. At this point, they relaxed for the reminder of the 10-s interval. During the cooling trial, stimulation blocks occurred during baseline, 20, 40, and $60 \mathrm{~min}$ of cooling, and following $30 \mathrm{~min}$ of rewarming. Subjective thermal sensation (Gagge et al. 1967) was recorded before every stimulation block as well as after the reassessment of $\mathrm{M}_{\max }$ and MVC period, prior to starting rewarming.

\section{Protocol}

Subjects visited the lab on 2 separate occasions, separated by at least 4 days. The first visit was the familiarization trial, while the second visit was the intervention trial (Fig. 1, top).

\section{Familiarization trial}

Before instrumentation, height (Model 439 Detecto Weight Beam Eye-Level, Detecto, Web City, MO, USA) and weight (InBody 270, InBody USA, Cerritos, CA, USA) were measured, and percentage of body fat was predicted using an InBody 270 bioelectric impedance body composition analyzer (InBody USA, Cerritos, CA, USA). Thermophysiological outcomes were not measured during this trial. However, the subjects were instrumented as per the familiarization trial described below. The LPS was worn throughout the trial but was not perfused until the last $10 \mathrm{~min}$ of the trial. Following instrumentation, the subjects performed MVCs of the elbow flexors. Stimulation intensities were established to elicit the $\mathrm{M}_{\text {max }}$, MEP, and CMEP.

One stimulation block was delivered prior to the $60-\mathrm{min}$ control period. During the $60-\mathrm{min}$ control period, the subjects sat in the stimulation chair wearing the LPS but it was not perfused. Stimulation blocks were then delivered at 20 and $60 \mathrm{~min}$. Following the 60-min stimulation block, the MVCs of the elbow flexors were reassessed. Subjects were then familiarized with brief 5-min 
Fig. 2. Raw electromyography (EMG) capture from a single subject during the first and last minute of 8-min EMG blocks at 3 time points (baseline, 0-8 min of cooling and 49-57 min of cooling). The 3 EMG channels (biceps brachii, triceps brachii, and rectus femoris) indicate no shivering activity during baseline and 0-8 min cooling, but shivering activity during $49-57$ min of cooling. // indicates that the EMG is continuous throughout the 8-min EMG block.

\section{Biceps brachii}

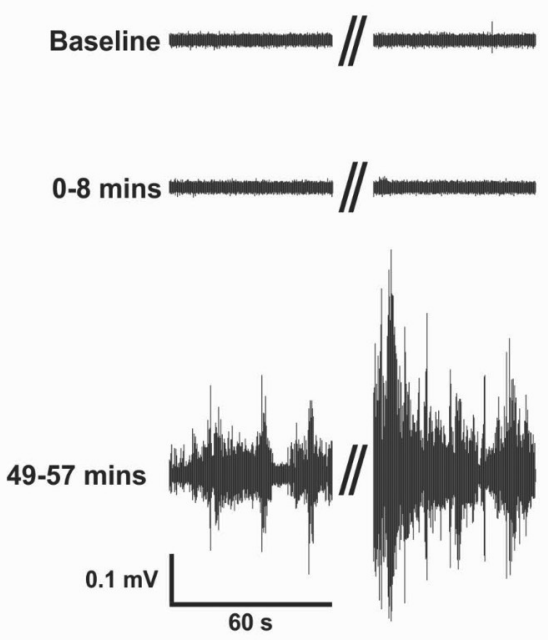

Triceps brachii
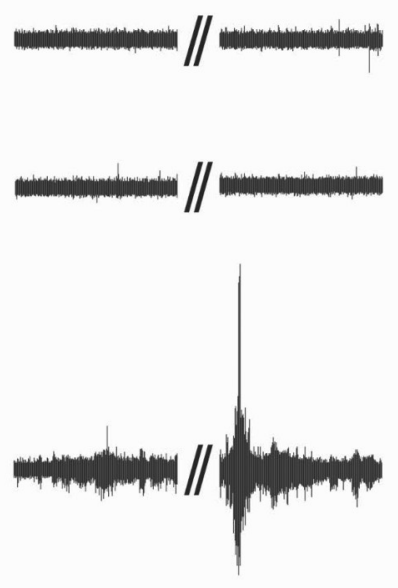

Rectus femoris
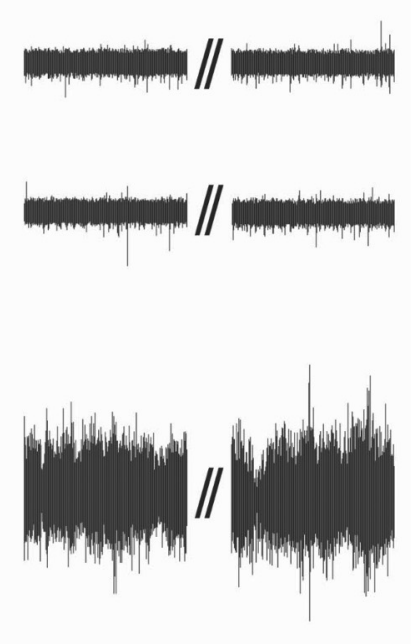

periods of LPS cooling $\left(9{ }^{\circ} \mathrm{C}\right.$ perfusate) and rewarming $\left(41{ }^{\circ} \mathrm{C}\right.$ perfusate).

\section{Intervention trial}

The subjects were instrumented, and the LPS was worn throughout the trial and was perfused as described below. The preliminary procedures were identical to the control trial, with the exception that, at the end of the preliminary procedures, an esophageal thermocouple was inserted.

Subjects sat quietly in the LPS without perfusion, while $8 \mathrm{~min}$ of baseline EMG activity of the biceps brachii, triceps brachii, and rectus femoris were collected (Fig. 1, top). Subjects were instructed to refrain from moving during this period and were reminded during all subsequent 8-min EMG captures to keep as still as possible. This allowed the detection of any cold-induced muscle tone and shivering activity during cooling. Shortly after baseline EMG measurements were made, a baseline stimulation block was conducted.

The LPS was connected to the chiller, which circulated $9{ }^{\circ} \mathrm{C}$ liquid, and the subjects were then cooled for $90 \mathrm{~min}$. EMG blocks (8 min) were collected during cooling from 0-8, 9-17, 29-37, and 49-57 min of cooling. Stimulation blocks occurred after 20, 40, and $60 \mathrm{~min}$ of cooling. A standard 3-min period between EMG and stimulation blocks was required to save the EMG data and prepare for the stimulation block.

Evidence that $\mathrm{M}_{\max }$ amplitude is altered following reductions in $T_{\text {sk }}$ and $T_{\text {mus }}$ are equivocal, as some studies have demonstrated decreases in $M_{\max }$ amplitude (Bell and Lehmann 1987), while others demonstrate increases (Dewhurst et al. 2005). Therefore, $M_{\max }$ was reassessed at the end of cooling and rewarming. These reassessments would allow post hoc interpretation of $\mathrm{M}_{\max }$ changes if they occur. These reassessment periods varied between subjects, as they took 18-29 min to complete. Active cooling continued, and rewarming did not start until reassessment was complete.

A final stimulation block was conducted after $30 \mathrm{~min}$ of rewarming. At this point, shivering was expected to be abolished, and $T_{\text {sk }}$ was expected to return to baseline. If $\mathrm{T}_{\text {es }}$ also returned to baseline, it would be possible to determine if any effects of cooling persisted. If $T_{\text {es }}$ remained decreased (as a variation of the afterdop phenomenon), the effects of central and peripheral cooling might be analyzed separately.

The LPS was then disconnected from the chiller and connected to the warm water reservoir, and $41{ }^{\circ} \mathrm{C}$ liquid was delivered to the LPS. The subjects were rewarmed for approximately $60 \mathrm{~min}$. Eightminute EMG blocks were recorded from 0-8 and 19-27 min of rewarming. A final stimulation block was initiated after $30 \mathrm{~min}$ of rewarming.

\section{Data analysis}

Baseline was defined as 5-min steady-state values at time $0 \mathrm{~min}$ for continuous data $\left(T_{\text {es }}\right.$ and $\left.T_{\text {sk }}\right)$. The initial MVCs, 8-min EMG block, and first stimulation block (prior to cooling) also served as baseline measures (Fig. 1, top).

The highest MVCs during the MVC assessments were recorded as the MVC value. The mean force for a $50-\mathrm{ms}$ window preceding each stimulation was calculated. Stimulations with preceding forces that did not match the goal force (within $4.75 \%$ to $5.25 \%$ MVC) were excluded from the analysis. Through this screening, only 21 of 1000 stimulations were omitted because the goal force was not obtained. To confirm that stimulation had occurred during similar levels of motor pool output, pre-stimulus EMG was analyzed by calculating the mean rectified signal over the same 50-ms window prior to stimulation.

Mean $T_{\text {sk }}$ and $T_{\text {es }}$ were monitored continuously and averaged every $30 \mathrm{~s}$ throughout the trial. The change in $T_{\mathrm{es}}$ was calculated as the change from baseline (time 0 ) values.

\section{Shivering detection}

Our analysis was not intended to assess the magnitude of shivering intensity, rather only the presence of shivering. Muscle EMG activity was visually monitored throughout the intervention trials and analyzed as described below. If an increased EMG activity was observed in any muscle, the subjects were asked if they were shivering. Verbal responses were noted.

The 8-min EMG blocks for each individual were visually inspected for evidence of increased activity and qualitatively graded as "no shivering" (e.g., Fig. 2 "baseline", and "0-8 min" cooling) or "shivering" (e.g., Fig. 2 "49-57 min" cooling). The number of 
subjects shivering at the time points of interest is indicated at the bottom of Fig. 1.

\section{Excitability}

For each stimulation block, the averages of the peak-to-peak amplitudes $(\mathrm{mV})$ of $\mathrm{M}_{\max }(n=2)$, CMEPs $(n=8)$, and MEPs $(n=10)$ were calculated. These averages are expressed as changes from baseline (\%). The average MEP and CMEP amplitudes were normalized to $\mathrm{M}_{\max }$ by presenting them as ratios $\left(\mathrm{MEP} / \mathrm{M}_{\max }\right.$ and $\left.\mathrm{CMEP} / \mathrm{M}_{\max }\right)$. These values provide insights into corticospinal excitability and account for changes that may have occurred in the excitability of the peripheral nerve (Hallett 2000; Terao and Ugawa 2002; Gruet et al. 2013). The EMG data for each stimulation were analyzed offline using Signal 7.0 software (Cambridge Electronic Design Ltd., Cambridge, UK).

All statistical analyses were performed using the SigmaStat package in SigmaPlot 14 (Systat Software, San Jose, CA, USA). One-way repeated-measures analysis of variance (ANOVA) was used to compare responses over time. This analysis was also applied to thermal sensation subjective scale data. Because this scale has 17 points (0-8 with allowable increments of 0.5$)$, the results were treated as interval data, thereby justifying a parametric analysis (Knapp 1990). Post hoc analyses for significant differences were accomplished using the Holm-Sidak post hoc test. All data are expressed as mean \pm SD. Statistical significance was set at $P<0.05$.

\section{Results}

Ten subjects (7 males, 3 females) completed the study. Two subjects (numbers 2 and 7) dropped out of the study, one because the esophageal probe could not be tolerated, and one because a reproducible MEP could not be obtained.

\section{Thermal responses}

Mean $T_{\text {sk }}$ was $32.5 \pm 0.6{ }^{\circ} \mathrm{C}$ during baseline and subsequently decreased to $22.9 \pm 2.0^{\circ} \mathrm{C}$ at $60 \mathrm{~min}(P<0.001)$ (Fig. 3a). Forehead temperature dropped only slightly, and the hands and feet dropped to approximately $25^{\circ} \mathrm{C}$. The 4 sites under the LPS decreased similarly with temperature, after 60-min of cooling, ranging from $15-21{ }^{\circ} \mathrm{C}$ for the calf and thigh, and $22-32{ }^{\circ} \mathrm{C}$ for the arm and abdomen. $T_{\text {sk }}$ did not change during the 18-29 min reassessment period $(P=0.99)$, but quickly increased and was restored to baseline values after $15 \mathrm{~min}$ of rewarming (mean of $31.3 \pm 1.0^{\circ} \mathrm{C}$ ). $T_{\mathrm{sk}}$ remained elevated and similar to baseline $\left(33.2 \pm 0.8^{\circ} \mathrm{C}\right)$ throughout the remainder of the rewarming period.

$\mathrm{T}_{\text {es }}$ was $37.1 \pm 0.3^{\circ} \mathrm{C}$ at baseline and did not change after $60 \mathrm{~min}$ of cooling $(P=0.92)$. However, $T_{\text {es }}$ did decrease significantly during continued cooling throughout the reassessment period, being lower than baseline by $0.6 \pm 0.6^{\circ} \mathrm{C}(P<0.001)$ (Fig. 3b). After $30 \mathrm{~min}$ of rewarming (when the final stimulation block was conducted), $T_{\text {es }}$ remained unchanged and was lower than baseline.

Baseline thermal sensation was rated as $4.2 \pm 0.5$ (neutral, comfortable) (Fig. 4). During all time points during cooling, thermal sensation was rated significantly colder than baseline $(P<0.001)$ with values at $60 \mathrm{~min}$ rated as $1.3 \pm 0.6$ (Cold - Very Cold). At the end of $30 \mathrm{~min}$ of rewarming, thermal sensation was restored to baseline values.

During cooling, 8 subjects shivered at some or all time points, as indicated by increased EMG activity (Fig. 1, bottom). In all cases where increased EMG activity prompted researchers to ask the subjects if they were shivering, the response was affirmative. During the reassessment period (when $T_{\text {es }}$ was decreasing), all 10 subjects self-reported shivering; shivering activity was visually confirmed in these subjects. Because EMG was not collected at this time in order to keep this period as short as possible, these results do not appear in Fig. 1 (bottom). During the first rewarming EMG block (88-96 min), 6 of 10 subjects were shivering at the beginning of the block. However, no shivering was observed at the end of the block.

\section{Elbow flexor MVCs}

Baseline elbow flexor MVC values did not differ between the familiarization and intervention trials $(P=0.12)$. On the intervention day, MVCs did not change from baseline (34 $\pm 9.1 \mathrm{~kg}$ ), to $60 \mathrm{~min}$ of cooling (31.4 $\pm 9.2 \mathrm{~kg})$, to the end of warming $(33.1 \pm 8.9 \mathrm{~kg})(P=0.81)$.

\section{Pre-stimulus EMG}

The level of EMG activity of the elbow flexors during the prestimulus 5\% MVCs did not differ within or between any stimulation blocks $(P=0.06)$. We also analyzed the background force just prior to the 5\% MVCs (presumably a result of background shivering activity). The background force was at most $0.74 \%$ of MVC; thus, the effect of shivering on voluntary drive was considered to be minimal.

$\mathbf{M}_{\max }$

Baseline $M_{\max }$ values did not differ between the familiarization and intervention trials $(P=0.83)$. In the familiarization trial, the $\mathrm{M}_{\max }$ amplitude did not change throughout the $60 \mathrm{~min}$ without thermal manipulation $(P=0.27)$. Likewise, in the intervention trial, it did not differ from baseline throughout $60 \mathrm{~min}$ of cooling or the end of rewarming $(P=0.52)$.

\section{MEPs}

Baseline values for $\mathrm{MEP} / \mathrm{M}_{\max }$ did not differ between the familiarization and intervention trials $(P=0.42)$. Subsequently, there were no changes throughout either the familiarization trial $(P=0.89)$ or the cooling period in the intervention trial $(P=0.19)$ (Figs. $5 a$ and 6).

\section{CMEP}

Baseline values for $\mathrm{CMEP} / \mathrm{M}_{\max }$ did not differ between the familiarization and intervention trials $(P=0.13)$. During the familiarization trial, CMEP/ $/ \mathrm{M}_{\max }$ did not differ from baseline after $20 \mathrm{~min}$, but was significantly lower after $60 \mathrm{~min}(P=0.03)$ (Fig. 5b).

During the intervention trial, $\mathrm{CMEP} / \mathrm{M}_{\max }$ increased by $79 \%$ after $60 \mathrm{~min}(P<0.001)$ and remained elevated by $71 \%$ at the end of rewarming $(P<0.001)$ (Figs. $5 b$ and 6$)$.

\section{Discussion}

To our knowledge, this is the first study to determine the effects of whole-body cooling on both corticospinal and spinal excitability in humans. Whole body cooling via a liquid-perfused suit $\left(\sim 9{ }^{\circ} \mathrm{C}\right)$ for 90 min reduced mean $T_{\text {sk }}$ to $\sim 23{ }^{\circ} \mathrm{C}$, while $T_{\text {es }}$ remained unchanged for $60 \mathrm{~min}$ but then decreased after $90 \mathrm{~min}$ by $\sim 0.6{ }^{\circ} \mathrm{C}$. Thermal comfort was rated as cold to very cold, while EMG analysis confirmed overt shivering in $80 \%$ of the subjects. Spinal excitability $\left(\mathrm{CMEP} / \mathrm{M}_{\max }\right)$ increased $\sim 79 \%$ above baseline values, whereas corticospinal excitability $\left(\mathrm{MEP} / \mathrm{M}_{\max }\right)$ remained unchanged. Perfusing the suit with $41^{\circ} \mathrm{C}$ water rapidly abolished shivering EMG activity as expected (Imbeault et al. 2013), and rewarmed $T_{\text {sk }}$ to baseline values within $15 \mathrm{~min}$. Despite the restoration of $T_{s k}, T_{e s}$ did not increase during this period. At this point, spinal excitability $\left(\mathrm{CMEP} / \mathrm{M}_{\max }\right)$ remained elevated by $71 \%$ compared with baseline, while corticospinal excitability $\left(\mathrm{MEP} / \mathrm{M}_{\max }\right)$ remained unchanged.

Increases in spinal excitability resulting from skin cooling in the present study are in agreement with several studies that observed increases in the $\mathrm{H}_{\max }: \mathrm{M}_{\max }$ ratio (another measure of spinal excitability) following ankle joint and leg skin cooling in young healthy adults (Oksa et al. 2000; Hopkins and Stencil 2002; Dewhurst et al. 2005; Palmieri-Smith et al. 2007). Additionally, the persistence of increased spinal excitability following the rewarming period (when $T_{\text {sk }}$ was restored to baseline, but $T_{\text {es }}$ was slightly reduced) is supported by animal studies that suggest that spinal cord cooling itself increases spinal excitability (Koizumi et al. 1960; Christensen and Perl 1970; Simon 1972; Brock and McAllen 2016). 
Fig. 3. (a) Mean skin temperature $\left(T_{\mathrm{sk}}\right)$ and $(b)$ change in esophageal temperature $\left(T_{\mathrm{es}}\right)$. Time 0 min indicates start of cooling. All subjects were cooled for $60 \mathrm{~min}$ at which point a stimulation block, reassessment of maximal compound motor action potential ( $\left.\mathrm{M}_{\text {max }}\right)$, and maximum voluntary contractions (MVCs) of biceps brachii and quadriceps were conducted. The time taken to conduct these measurements varied between individuals (range 18-29 min). Rewarming did not commence until these measurements were complete. To show how the whole group responded at the beginning and the end of the reassessment period, data for the periods shorter than 29 min are presented for the first $5 \mathrm{~min}$, with the remainder adjusted so that the time for the start of rewarming aligns for everyone at $89 \mathrm{~min}$. As a result, $n=10$ for data from 60 to $65 \mathrm{~min}$ and from 76 to $89 \mathrm{~min}$. In the period between 65 to $76 \mathrm{~min}, n$ ranges from 1 to 8 . Error bars represent SD. *, value is different from baseline; $\dagger$, value is different from $20 \mathrm{~min}$ of cooling; $\ddagger$, value is different from start of rewarming $(89 \mathrm{~min})(P<0.05)$.

a)
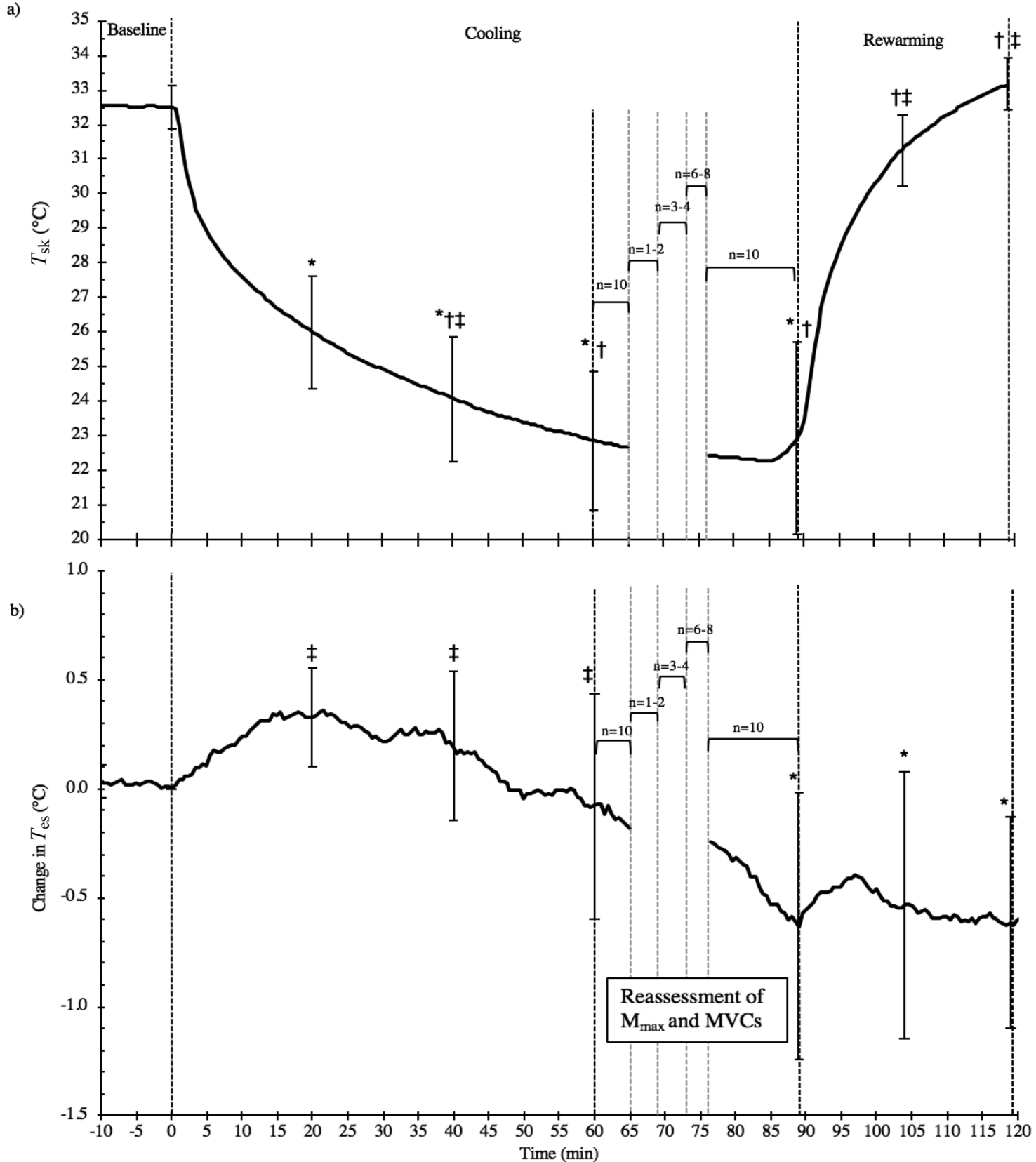

The fact that corticospinal excitability $\left(\mathrm{MEP} / \mathrm{M}_{\max }\right)$ did not change during both the cooling period (reduced $\mathrm{T}_{\mathrm{sk}}$, normal $\mathrm{T}_{\mathrm{es}}$ ), and the rewarming period (reduced $T_{\text {es }}$, normal $T_{\text {sk }}$ ) is consistent with the study of Cahill et al., who observed no change in MEP/ $\mathrm{M}_{\max }$ of the biceps brachii after $60 \mathrm{~min}$ immersion in $8^{\circ} \mathrm{C}$ water, which reduced both $T_{\text {sk }}$ and $T_{\text {es }}$ (Cahill et al. 2011). During cooling, increased spinal excitability was likely driven by the activation of cutaneous cold receptors, whereas during rewarming, the persistence of excitability despite a restoration of $T_{\mathrm{sk}}$ to baseline indicates that internal (or spinal) cold receptors were likely activated, facilitating spinal excitability. It is noteworthy that both these studies involved whole-body cooling, which decreased $T_{\text {es }}$. Other studies involving local cooling of smaller areas (without a change in $T_{\text {es }}$ ) showed a varied response. Ansari et al. demonstrated that with finger cooling, MEP amplitude decreased in one-third of subjects; however, it actually increased in one-half of the subjects (Ansari et al. 2018a). This group also observed a consistent reduction in MEP amplitude following local hemi-scalp 
Fig. 4. Thermal sensation. Time 0 min indicates start of cooling. All subjects were cooled for 60 min at which point a stimulation block, reassessment of maximal compound motor action potential $\left(\mathrm{M}_{\max }\right)$ and maximum voluntary contractions (MVCs) of biceps brachii and quadriceps, were conducted. The time taken to conduct these measurements varied between individuals (range 18-29 min). Rewarming did not commence until these measurements were complete. To show how the whole group responded at the beginning and the end of the reassessment period, data for the periods less than 29 min are presented for the first 5 min, with the remainder adjusted so that the time for the start of rewarming aligns for everyone at $90 \mathrm{~min}$. As a result, $n=10$ for data from 60 to $65 \mathrm{~min}$ and from 80 to 90 min. In the period between 65 to $80 \mathrm{~min}, n$ ranges from 4 to 9 . Error bars represent SD. *, value is different from baseline; $\dagger$, value is different from $20 \mathrm{~min}$ of cooling; $\ddagger$, value is different from start of rewarming $(90 \mathrm{~min})(P<0.05)$.

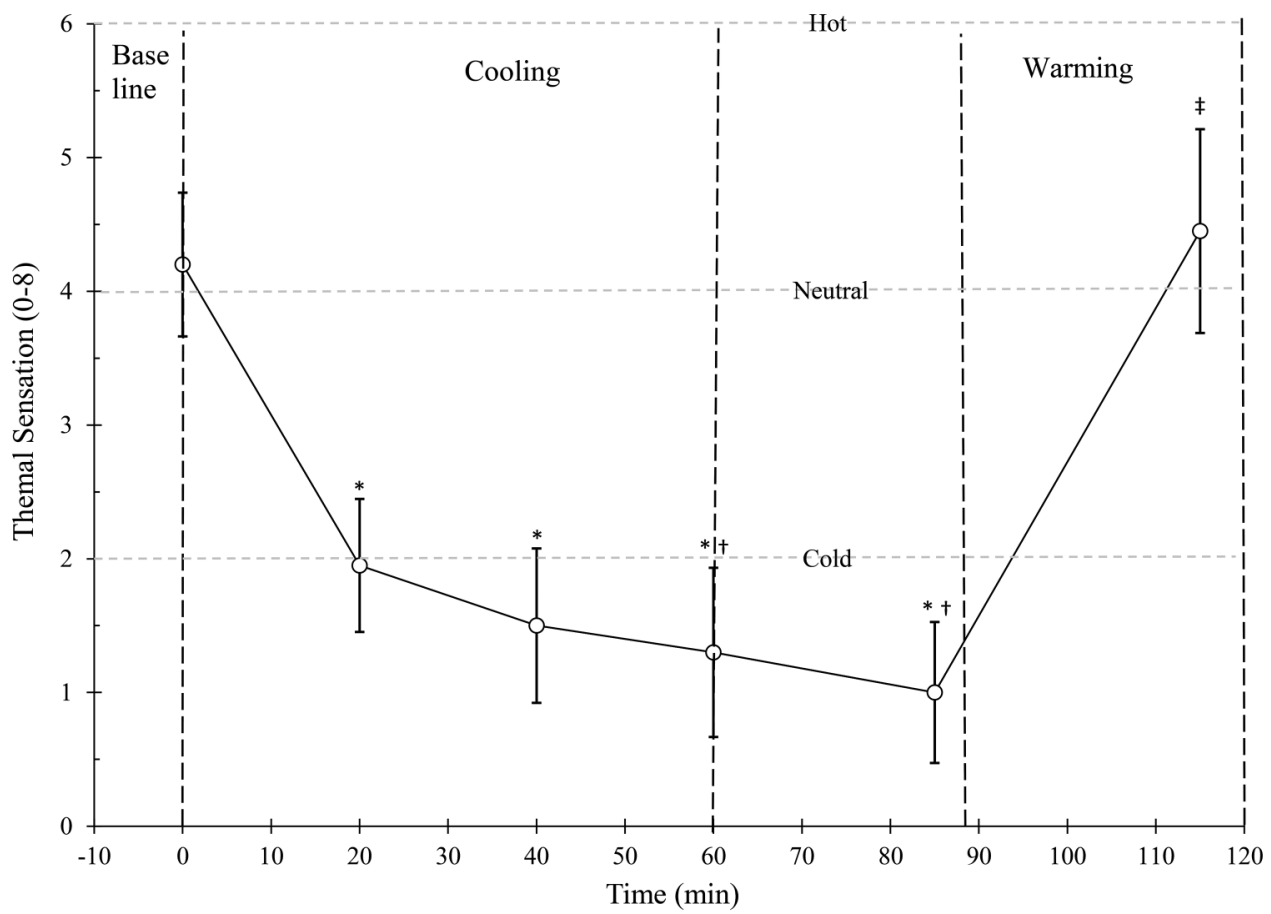

cooling; it is not known if this reduction is related to the cooling area being adjacent to the TMS stimulation area (Tremblay et al. 2015).

In response to skin cooling, although activation and inactivation of various ion channels involved in temperature regulation (i.e., TRPM, TREK, and TRAAK channels) could have contributed to the changes in spinal neural activity, it is difficult to propose any explanation because of the lack of recognition of these ion channels in terms of influencing neural activity in human ventral spinal circuits. Based on the measured $\mathrm{T}_{\text {sk }}$ (e.g., between 15 and $26{ }^{\circ} \mathrm{C}$ ), no heat- or cold-sensitive polymodal C-nociceptor afferents are expected to be significantly activated in healthy humans. Activation of the autonomic nervous system may have contributed to our responses. However, we had no measurements in place to conclude anything related to its involvement, but its contribution, as suggested in previous studies, cannot be excluded (Oksa et al. 2000; Dewhurst et al. 2005; Hopkins and Stencil 2002; Palmieri-Smith et al. 2007; Buharin et al. 2013).

Although $T_{\text {sk }}$ was restored during the rewarming period, a reduced $T_{\text {es }}$ implied that central tissues, such as the spinal cord, were cooled. In animal studies, direct spinal cooling has been shown to increase the excitability of spinal neurons, possibly through mechanisms such as increasing the duration of the action potential (increasing the likelihood of summation to occur), increasing the excitability of interneurons, and/or changing the threshold for firing (Koizumi et al. 1960; Simon 1972). Although some animal studies suggest that elevating the ambient temperature to $\sim 30^{\circ} \mathrm{C}$, and therefore increasing $T_{\text {sk }}$, attenuates spinal excitability through a reduction in cold transmission at the dorsal horn (Brock and McAllen 2016), it is unknown if this phenomenon occurs in humans.
The unchanged $\mathrm{MEP} / \mathrm{M}_{\max }$ in isolation indicates that the overall corticospinal excitability was unchanged. However, MEP generation requires TMS transmission from the cortical to spinal neurons and motoneurons. Therefore, an unchanging $\mathrm{MEP} / \mathrm{M}_{\max }$ could be indicative of reduced cortical and/or supraspinal excitability, which is compensated for by downstream increased transmission at the level of the brainstem and/or spinal neurons. This possibility could be explored in a separate study using paired-pulse TMS.

\section{Significance of the results}

This study demonstrated that mild whole-body cooling increased spinal excitability, while overall corticospinal excitability remained unchanged. This is important given the fact that the cold-induced decrease in performance is approximately $85 \%-90 \%$ due to local effects of cooling, and 10\%-15\% due to central effects (Giesbrecht et al. 1995). This study now has identified that any decrease in performance could be compensated by increased spinal excitability, to provide a performance and survival advantage, at least under the cooling protocol performed here. Therefore, it would be valuable to determine the effects of moderate-to-severe cooling on these central mechanisms, as this would be more reflective of a cold survival scenario. In future studies, however, differentiating between corticospinal and spinal excitability would be important considering the results presented here.

\section{Potential limitations}

This protocol does not allow TMS and TMES of multiple muscles; therefore, all measures of excitability are based on a single proximal muscle. It may be of interest to separately determine the effects of 
Fig. 5. (a) Change in maximal compound motor action potential $\left(\mathrm{M}_{\max }\right)$; (b) motor evoked potential (MEP)/ $\mathbf{M}_{\max }$; and (c) cervicomedullary evoked potential (CMEP)/ $\mathrm{M}_{\text {max }}$. During the control trial (black line), subjects sat in the stimulation chair for 60 min wearing the liquidperfused suit without perfusion turned on. Stimulation blocks were conducted at 0, 20, and 60 min. During the cooling trial (blue line), time 0 min indicates start of cooling. Cooling continued through the reassessment of $\mathrm{M}_{\max }$ and maximum voluntary contractions (MVCs), and rewarming begins at $89 \mathrm{~min}$. Error bars represent SD. *, value is different from baseline within trial; $\dagger$, value is different from $40 \mathrm{~min}$ of cooling within trial $(P<0.05)$.

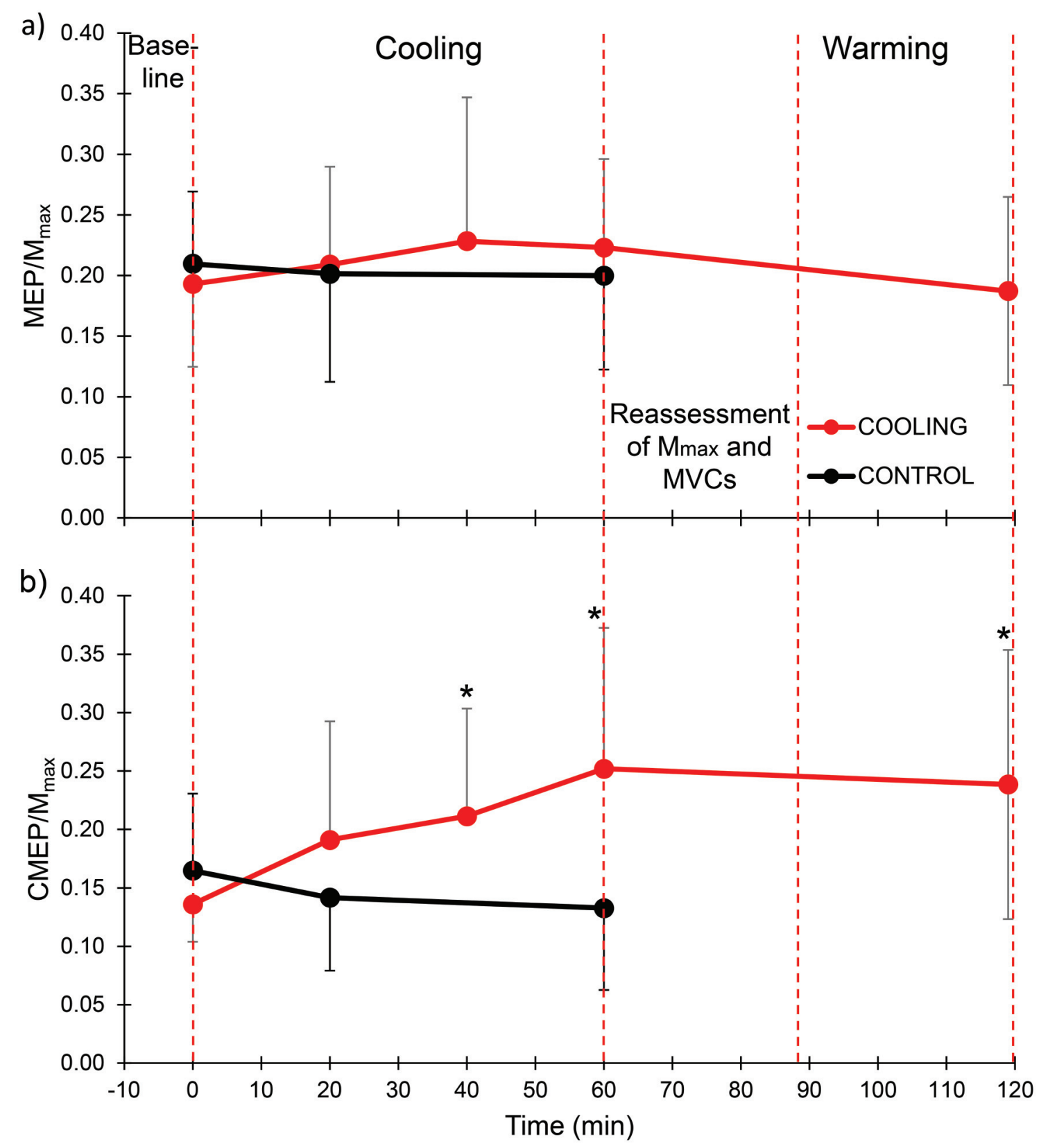

cooling on other muscles (e.g., either on the lower body or smaller muscle groups in the hand).

As shivering intensity increases, so does background EMG activity (Israel and Pozos 1989; Bell et al. 1992). Given that increases in tonic contraction intensity facilitate both CMEP (Taylor et al. 2002; Taylor and Gandevia 2004; Pearcey et al. 2014) and MEP measurements (Ugawa et al. 1995; Lazzaro et al. 1998), it is possible that shivering itself played a role in our observation of increased CMEP amplitudes. However, if this were the case, we would expect corticospinal $\left(\mathrm{MEP} / \mathrm{M}_{\max }\right)$ amplitudes to also be facilitated, but they were not. Additionally, our protocol utilized a 3-s isometric contraction of the elbow flexors at 5\% MVC. Our consistent level of pre-stimulus EMG activity confirms that activation of the biceps brachii was consistent prior to all stimulations. In addition, we determined that the background coldinduced EMG activity was at most $0.74 \%$ MVC; thus, the effect of shivering on voluntary drive was considered to be minimal. However, we still cannot account for the effects that shivering activity of other muscles may have had on corticospinal and spinal excitability.

Our protocol only allowed us to assess corticospinal and spinal excitability during reduced $T_{\text {sk }}$ or $T_{\text {es }}$, but not both at the same time. This would be valuable, as in real-world survival situations, where $T_{\text {sk }}$ is reduced whenever $T_{\text {es }}$ is reduced (e.g., accidental 
Fig. 6. Raw biceps brachii electromyography (EMG) trace for a single subject of the average motor evoked potential (MEP) $(n=10$ stimulations) and cervicomedullary evoked potential (CMEP) ( $n=8$ stimulations) at baseline (time $0 \mathrm{~min}$ ) and when shivering (60 min post-cooling). Stimulus artifacts have been truncated to preserve scaling of the $y$-axis. $\mathrm{M}_{\max }$, maximal compound motor action potential.

\section{Baseline $\quad 60$ Mins Post}

MEP
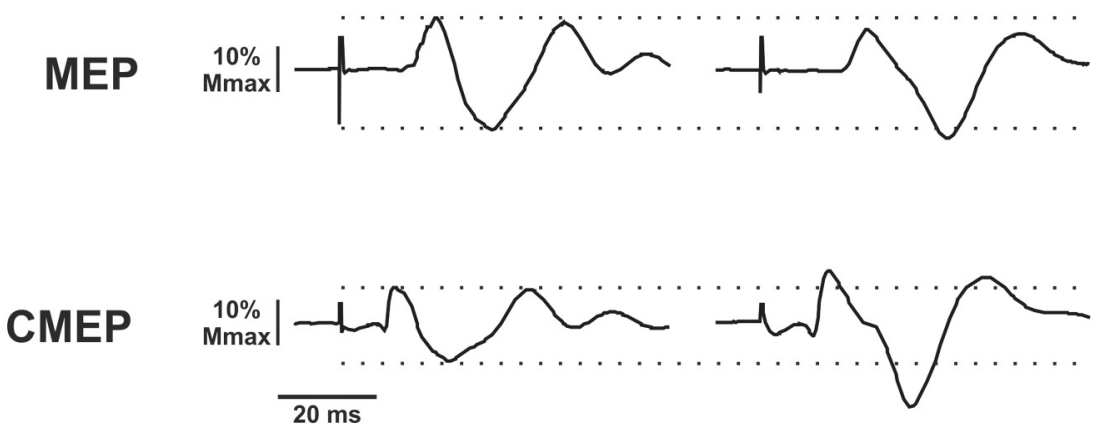

hypothermia). Future studies should involve longer or more intense cooling to conduct a stimulation block when both $T_{\text {sk }}$ and $T_{\text {es }}$ are reduced.

Finally, although 3 female subjects completed the study, it was not powered to detect sex differences. Qualitatively, responses were similar between sexes, but future studies should confirm whether differences exist between females and males.

\section{Conclusion}

In conclusion, this study is the first to characterize both corticospinal and spinal excitability during whole-body cooling and rewarming. Our protocol allowed us to identify the effects of reduced $T_{\text {sk }}$ or reduced $T_{\text {es }}$ during warming, separately on corticospinal and spinal excitability, and found that spinal excitability was facilitated, while corticospinal excitability remained unchanged in both conditions. Future research could isolate and compare the effects of cooling different regions (such as head vs. whole body cooling) on corticospinal and spinal excitability. Future studies could also use different techniques (e.g., pair pulse TMS) to focus on the isolated effect of cooling on cortical excitability. Additionally, employing cooling protocols with greater intensity and/or longer durations would induce physiological states that are more relevant in survival or clinical situations (e.g., reduced $\mathrm{T}_{\mathrm{sk}}$ and $\mathrm{T}_{\mathrm{es}}$ ) and would better allow generalization of results to real-world situations.

\section{Conflict of interest statement}

The authors declare no conflicts of interest. The results of this study are presented clearly, honestly, and without fabrication, falsification, or inappropriate data manipulation.

\section{Acknowledgements}

We thank the participants for their time, discomfort, and effort. Financial support was obtained from the Natural Science and Engineering Research Council (NSERC), Canada. Author contributions: D.M.G.H., K.P., and G.G.G. were involved in the conception and design of the work. D.M.G.H., M.T.n., K.S., E.L., K.P., P.G., and G.G.G. were all involved in the acquisition of data, analysis, and interpretation. D.M.G.H., M.T.n., K.P., K.S., P.G., and G.G.G. critically revised the important intellectual content.

\section{References}

Aboodarda, S.J., Copithorne, D.B., Pearcey, G.E.P., Button, D.C., and Power, K.E. 2015. Changes in supraspinal and spinal excitability of the biceps brachii following brief, non-fatiguing submaximal contractions of the elbow flexors in resistance-trained males. Neurosci. Lett. 607: 66-71. doi:10.1016/j.neulet.2015. 09.028. PMID:26415709.
Ansari, Y., Remaud, A., and Tremblay, F. 2018a. Modulation of corticomotor excitability in response to distal focal cooling. PeerJ. 6: e6163. doi:10.7717| peerj.6163. PMID:30595991.

Ansari, Y., Remaud, A., and Tremblay, F. 2018b. Variations in corticomotor excitability in response to distal focal thermal stimulation. Somatosen. Mot. Res. 35: 69-79. doi:10.1080/08990220.2018.1460263. PMID:29649910.

Anttonen, H., Pekkarinen, A., and Niskanen, J. 2009. Safety at work in cold environments and prevention of cold stress. Ind. Health, 47: 254-261. doi:10.2486/ indhealth.47.254. PMID:19531911.

Bell, D.G., Tikuisis, P., and Jacobs, I. 1992. Relative intensity of muscular contraction during shivering. J. Appl. Physiol. 72: 2336-2342. doi:10.1152/ jappl.1992.72.6.2336. PMID:1629089.

Bell, K.R., and Lehmann, J.F. 1987. Effect of cooling on H-and T-reflexes in normal subjects. Arch. Phys. Med. Rehab. 68: 490-493. PMID:3619611.

Blondin, D.P., Daoud, A., Taylor, T., Tingelstad, H.C., Bézaire, V., Richard, D., et al. 2017. Four-week cold acclimation in adults humans shifts uncoupling thermogenesis from skeletal muscles to brown adipose tissue. J. Physiol. 595(6): 2099-2113. doi:10.1113/JP273395. PMID:28025824.

Brock, J.A., and Mcallen, R.M. 2016. Spinal cord thermosensitivity: An afferent phenomenon? Temperature, 3: 232-239. doi:10.1080/23328940.2016.1157665. PMID:27857953.

Buharin, V.E., Butler, A.J., Rajendra, J.K., and Shinohara, M. 2013. Enhanced corticospinal excitability with physiologically heightened sympathetic nerve activity. J. Appl. Physiol. 114: 429-435. doi:10.1152/japplphysiol.01586.2011. PMID:23239871.

Cahill, F., Kalmar, J.M., Pretorius, T., Gardiner, P.F., and Giesbrecht, G.G. 2011. Whole-body hypothermia has central and peripheral influences on elbow flexor performance. Exp Physiol. 96: 528-538. doi:10.1113/expphysiol. 2010.054973. PMID:21378082.

Castellani, J.W., and Tipton, M.J. 2015. Cold stress effects on exposure tolerance and exercise performance. Compr. Physiol. 6: 443-469. doi:10.1002/ cphy.c140081. PMID:26756639.

Cheung, S.S., Montie, D.M., White, M.D., and Behm, D. 2003. Changes in manual dexterity following short term hand forearm immersion in 10 degree $C$ water. Aviat Space Environ. Med. 74: 990-993. PMID:14503680.

Christensen, B., and Perl, E.J.J.O.N. 1970. Spinal neurons specifically excited by noxious or thermal stimuli: marginal zone of the dorsal horn. J. Neurophysiol. 33(2), 293-307. doi:10.1152/jn.1970.33.2.293. PMID:5415075.

Crone, C., Hultborn, H., Mazières, L., Morin, C., Nielsen, J., and PierrotDeseilligny, E. 1990. Sensitivity of monosynaptic test reflexes to facilitation and inhibition as a function of the test reflex size: a study in man and the cat. Exp. Brain Res. 81(1), 35-45. doi:10.1007/BF00230098. PMID:2394229.

de Jong, R.H., Hershey, W.N., and Wagman, I.H. 1966. Nerve conduction velocity during hypothermia in man. Anesthesia, 27: 805-810. doi:10.1097| 00000542-196611000-00013. PMID:5924554

Dewhurst, S., Riches, P.E., Nimmo, M.A., and De Vito, G. 2005. Temperature dependence of soleus H-reflex and $\mathrm{M}$ wave in young and older women. Eur. J. Appl. Physiol. 94: 491-499. doi:10.1007/s00421-005-1384-6. PMID:15952024.

Faulkner, J.A., Zerba, E., and Brooks, S.V. 1990. Muscle temperature of mammals: cooling impairs most functional properties. Am. J. Physiol. 259: R259-265. doi:10.1152/ajpregu.1990.259.2.R259. PMID:2386236.

Gagge, A., Stolwijk, A., and Hardy, J. 1967. Comfort and thermal senations and associated physiological responses at various ambient temperatures. Environ. Res. 1: 1-20. doi:10.1016/0013-9351(67)90002-3. PMID:5614624.

Giesbrecht, G.G., and Bristow, G.K. 1992. Decrement in manual arm performance during whole body cooling. Aviat. Space Environ. Med. 63: 1077-1081. PMID:1456919. 
Giesbrecht, G.G., Ming Pu, W., White, M.D., Johnston, C.E., and Bristow, G.K. 1995. Isolated effects of peripheral arm and central body cooling on arm performance. Aviat. Space Environ. Med. 66: 968-975. PMID:8526834.

Gruet, M., Temesi, J., Rupp, T., Levy, P., Millet, G.Y., and Verges, S. 2013. Stimulation of the motor cortex and corticospinal tract to assess human muscle fatigue. Neuroscience, 231: 384-399. doi:10.1016/j.neuroscience.2012.10.058. PMID:23131709.

Hallett, M. 2000. Transcranial magnetic stimulation and the human brain. Nature, 406: 147-150. doi:10.1038/35018000. PMID:10910346.

Haman, F., Legault, S.R., and Weber, J.M. 2004. Fuel selection during intense shivering in humans: EMG pattern reflects carbohydrate oxidation. J. Physiol. 556: 305-313. doi:10.1113/jphysiol.2003.055152. PMID:14742724.

Hayward, J.S., Eckerson, J.D., and Kemna, D. 1984. Thermal and cardiovascular changes during three methods of resuscitation from mild hypothermia. Resuscitation, 11: 21-33. doi:10.1016/0300-9572(84)90031-5. PMID:6322264.

Hopkins, J.T., and Stencil, R. 2002. Ankle cryotherapy facilitates soleus function. J. Orthop. Sports Phys. Ther. 32: 622-627. doi:10.2519/jospt.2002.32.12.622. PMID: 12492271.

Hurrie, D.M.G., and Giesbrecht, G.G. 2018. Is active recovery during cold water immersiion bettern than active or passive recovery in thermoneutral water for post-recovery high intensity exercises performance? Appl. Physiol. Nutr. Metab. 45(3): 251-257. doi:10.1139/apnm-2019-0189. PMID:31314993.

Imbeault, M.A., Mantha, O.L., and Haman, F. 2013. Shivering modulation in humans: Effects of rapid changes in environmental temperature. J. Therm. Biol. 38: 582-587. doi:10.1016/j.jtherbio.2013.10.002.

Israel, D.J., and Pozos, R.S. 1989. Synchronized slow-amplitude modulations in the electromyograms of shivering muscles. J. Appl. Physiol. 66: 23582363. doi:10.1152/jappl.1989.66.5.2358. PMID:2745301.

Knapp, R.T. 1990. Treating ordinal scales as interval scales: An attempt to resolve the controversy. Nursing Res. 39: 121-123. PMID:2315066.

Koizumi, K., Ushiyama, J., and Brooks, C. 1960. Effect of hypothermia on excitability of spinal neurons. J. Neurophysiol, 23: 421-431. doi:10.1152/jn. 1960.23.4.421. PMID:14410599.

Layton, R., Mints, W.J., Annis, J., Rack, M., and Webb, P. 1983. Calorimetry with heat flux transducers: comparison with a suit calorimeter. J. Appl. Physiol. 54: 1361-1367. doi:10.1152/jappl.1983.54.5.1361. PMID:6863096.

Lazzaro, V.D., Restuccia, D., Oliviero, A., Profice, P., Ferrara, L., Insola, A., et al. 1998. Magnetic transcranial stimulation at intensities below active motor threshold activates intracortical inhibitory circuits. Exp. Brain Res. 119: 265-268. doi:10.1007/s002210050341. PMID:9535577.

Lloyd, A., and Havenith, G. 2016. Interactions in human performance: An individual and combined stressors approach. Temperature (Austin), 3: 514-517. doi:10.1080/23328940.2016.1189991. PMID:28090553.

McNeil, C., Butler, J., Taylor, J., and Gandevia, S. 2013. Testing the excitability of human motoneurons. Front. Hum. Neurosci. 7: 152. doi:10.3389/fnhum.2013. 00152. PMID:23630483.
Oksa, J., Rintamaki, H., Makinen, T., Martikkala, V., and Rusko, H. 1996. EMGactivity and muscular performance of lower leg during stretch-shortening cycle after cooling. Acta Physiol. Scand. 157: 1-8. doi:10.1046/j.1365-201X.1996. 452172000.x. PMID:8735656.

Oksa, J., Rintamaki, H., Rissanen, S., Rytky, S., Tolonen, U., and Komi, P. 2000. Stretch-and H-reflexes of the lower leg during whole body cooling and local warming. Aviat. Space Environ. Med. 71: 156-161. PMID:10685590.

Oldfield, R.C. 1971. The assessment and analysis of handedness: The Edinburgh inventory. Neuropsychologia, 9: 97-113. doi:10.1016/0028-3932(71)90067-4. PMID:5146491.

Palmieri-Smith, R.M., Leonard-Frye, J.L., Garrison, C.J., Weltman, A., and Ingersoll, C.D. 2007. Peripheral joint cooling increases spinal reflex excitability and serum norepinephrine. Int. J. Neuroscience, 117: 229-242. doi:10. 1080/00207450600582702. PMID:17365110.

Pearcey, G.E., Power, K.E., and Button, D.C. 2014. Differences in supraspinal and spinal excitability during various force outputs of the biceps brachii in chronic-and non-resistance trained individuals. PLoS ONE, 9: e98468. doi:10.1371/journal.pone.0098468. PMID:24875495.

Pierrot-Deseilligny, E., and Mazevet, D. 2000. The monosynaptic reflex: a tool to investigate motor control in humans. Interest and limits. Neurophysiol. Clin. 30: 67-80. doi:10.1016/S0987-7053(00)00062-9. PMID:10812576.

Simon, E. 1972. Temperature signals from skin and spinal cord converging on spinothalamic neurons. Pflugers. Arch. 337: 323-332. doi:10.1007/BF00586649. PMID:4674881.

Stefanelli, L., Lockyer, E.J., Collins, B.W., Snow, N.J., Crocker, J., Kent, C., et al. 2019. Delayed onset muscle soreness and topical analgesic alter corticospinal excitability of the biceps brachii. Med. Sci. Sports Exerc. 51: 2344-2356. doi:10.1249/MSS.0000000000002055. PMID:31157708.

Taylor, J.L., and Gandevia, S.C. 2004. Noninvasive stimulation of the human corticospinal tract. J. Appl. Physiol. 96: 1496-1503. doi:10.1113/jphysiol.2002. 016782, doi:10.1152/japplphysiol.01116.2003. PMID:15016794.

Taylor, J., Petersen, N., Butler, J., and Gandevia, S. 2002. Interaction of transcranial magnetic stimulation and electrical transmastoid stimulation in human subjects. J. Physiol. 541: 949-958. doi:10.1113/jphysiol.2002.016782. PMID:12068053.

Terao, Y., and Ugawa, Y. 2002. Basic mechanisms of TMS. J. Clin. Neurophysiol. 19: 322-343. doi:10.1097/00004691-200208000-00006. PMID:12436088.

Tremblay, F, Remaud, A, Mekonnen, A, Gholami-Boroujeny, S., Racine, KT. and Bolic, M. 2015. Lasting depression in corticomotor excitability associated with local scalp cooling. Neurosci. Lett. 600: 127-131. doi:10.1016/j.neulet.2015. 06.008. PMID:26067406.

Ugawa, Y., Terao, Y., Hanajima, R., Sakai, K., and Kanazawa, I. 1995. Facilitatory effect of tonic voluntary contraction on responses to motor cortex stimulation. Electroencephalogr Clin Neurophysiol, 97: 451-454. doi:10.1016/0924980X(95)00214-6. PMID:8536598. 